\section{The writing is on the wall}

\section{S. F. Blinkhorn}

JUST as the handwritten letter is about to succumb to competition from the word processor, there seems to be a growing trend for companies to ask potential recruits for applications completed in their own handwriting. This is nothing to do with a sudden upsurge in aesthetic sensitivity on the part of personnel managers. One need look no further for an explanation than the marketing activities of graphologists.

Graphologists claim to be able to discern character and suitability for employment from handwriting. The claim finds a ready audience in the higher reaches of business, in particular in financial institutions. In continental Europe - especially France - the influence of graphologists is reputedly pervasive, although credible statistics are hard to come by and organizations that are believed on good grounds to use their services will often refuse to acknowledge the fact.

These practitioners, who are organized in competing professional associations, present their findings as matters of fact not opinion and lay claim to diagnostic skill of a high order. A statement produced today by the British Psychological Society (BPS)* presents a contrary view. Drawing together findings from published empirical work, it presents an unremittingly negative picture of the value of graphology in personnel assessment. Copies of the statement have been sent to the Secretary of State for Employment, the House of Commons Select Committee on Employment, the Commission for Racial Equality, the Equal Opportunities Commission and the Institute of Personnel Management, in the hope of opening up the issue of whether the use of graphology constitutes unfair employment practice.

It is not for want of trying that no persuasive evidence has been found. Researchers have tried to find associations between the judgements of graphologists and scores on a variety of psychological tests. They have looked for relationships with the criteria used in a full-scale assessment centre being run live as part of a selection procedure, and with supervisorrated performance. They have sought confirmation of the claim that people's occupations can be identified from their script.

In 1961 Fluckinger et al. ${ }^{1}$ reviewed experimental work so far and concluded that evidence "for the relationship of graphological inferences with criteria of interest remained fragmentary". By 1983 Klimoski et $a .^{2}$ had this to say: "the general trend of findings is to suggest that

* The British Psychological Society, St Andrews House, 48 Princess Road East, Leicester LE1 7DR, UK. graphology is not a viable assessment method". In 1986 Ben-Shakhar et al. ${ }^{3}$ wrote that "when graphologists base their judgements on spontaneously produced text. ... they can achieve positive, if small, validities. However, when nongraphologists analyse the same data, they achieve similar validities. So does a naive and clearly nonoptimal linear model of the information used in those texts." The most recent study mentioned, in 1991, is almost plaintive: "we have tried our utmost but have failed to provide evidence to support the use of graphology for personnel assessment" 4

Why should anyone suppose that calligraphy and character are close-coupled? It is easy to show that there is more to handwriting than a peripheral motor habit. Try writing with your non-preferred hand, or with a pen gripped between your toes or strapped to your elbow, and the result is recognizable as a poor attempt at your normal hand. In some sense, handwriting involves templates or models that are represented at a reasonably high level in the central nervous system.

Chronic conditions such as Parkinsonism or Korsakoff's syndrome have an obvious effect on handwriting, and no doubt an experienced eye can detect the effects of short-term stress. There are also those who claim to be able to detect the sex of a writer from the form his or her script takes - completed examination papers provide a regular anonymous source of experimental material for studies of this kind. And where the initial teaching of handwriting is done to a standard national pattern, as for instance in France, there may be an argument that the development of a personalized script will necessarily reflect the ways in which the personality of the individual departs from the average. Finally, there are of course students of handwriting whose skill at detecting forgery or disguised writing is relied upon by the courts as a matter of evidence.

All of this supports the view that handwriting is personal, is more or less consistently identifiable, and may possibly reflect important facts about its producer. Indeed, handwriting is part of selfpresentation. What is dubious is the link between elements of letter formation, slant, size and neatness and supposed personal qualities.

You will not, in the work of graphologists, find quantified judgements of differences among individuals with respect to a fixed set of characteristics. Instead their work is best characterized as epithet plucking. This applicant is honest, hardworking and open to experience, while that applicant is rather over-anxious but creative and imaginative. This is the method of the literary character sketch, where much is left to the imagination of the reader, and where in any case its subject is fictional. Film adaptations of great novels are often disappointing precisely because much of the characterization is missing or seems a misreading to those who have previously read the book.

Psychologists long ago discovered, in what is pompously known as the Fallacy of Personal Validation (or the Barnum Effect, to give it its everyday name, for it only goes to show that there's a sucker born every minute), the poor critical skills we bring to bear on character descriptions of this kind. There are some descriptions ("not always as extrovert as you sometimes appear"; "usually able to rise to the challenge of problems you meet") which nearly everyone, nearly always, nearly everywhere believes to be true of themselves. If, as part of the sales pitch, you are offered a reading of your own character, do not be surprised at its apparent accuracy and relevance, indeed its apparently privileged access to facts about your character you thought you had kept well hidden. This is a party trick. It involves describing the human condition. There is a long and occasionally entertaining research literature on the topic.

Another popular sales ploy with graphologists is to relate how they detected dishonesty in a sample of handwriting, and - wonder to behold - the writer had at some time in the past been convicted of a criminal offence. The sceptic might wonder what fraction of potential applicants had committed what were in a strict sense crimes, but remained undetected or unindicted.

The point is that graphology operates on a naive unreconstructed commonsense view of personality, and so produces accounts that seem readily comprehensible to prospective punters. In doing so, it makes no concessions to scientific methodology or standards, and, as the BPS's statement makes clear, when it is put to the test it fails. That is not to say that all that is needed for effective personnel selection is a sophisticated reconstructed scientific view of personality: psychologists are not without $\sin$ in the claims they make. But graphology is a target at which they can safely throw stones.

S. F. Blinkhorn is at Psychometric Research and Development Ltd, Brewmaster House, The Maltings, St Albans, Hertfordshire AL1 3HT, UK.

\footnotetext{
Fluckinger, F. A., Tripp, C. A. \& Weinberg, G. H. Percept Mot. Skills 12, 67-90 (1961).

. Klimoski, R. J. \& Rafaeli, A. J. occup. Psychol. 56. 191-202 (1983)

3. Ben-Shakhar, G., Bar-Hillel, M., Bilu, Y., Ben-Abba, E. \& Flug, A. J. appl. Psychol. 71, 645-653 (1986).

4. Cox, J. \& Tapsell, J. Pap. pres. Occupational Psychology Cox, J. \& Tapsell, J. Pap. pres. Occupat
Conf. BPS, Cardiff, 5 January 1991.
} 